\title{
Hubungan Karakter Komponen Hasil Dan Daya Hasil Lateks dari Beberapa Genotipe Karet Harapan PP/07/04
}

\section{The Correlation of Yield Component and Latex Yield Characters of Some Promising Rubber Genotypes PP/07/04}

\author{
Sayurandi \\ Balai Penelitian Sungei Putih, Pusat Penelitian Karet \\ Po BOX 1415 Medan 20001 \\ E-mail: sayurandi@gmail.com
}

\begin{abstract}
ABSTRAK
Tujuan dari penelitian ini adalah untuk mengetahui hubu gan karakter komponen hasil dan daya hasil lateks beberapa genotipe karet harapan PP/07/04. Sebanyak lima genotipe ditanam pada pengujian Plot Promosi di Kebun Percobaan Sungei Putih pada tahun 2004. Karakter yang diamati pada penelitian ini meliputi karakter pertumbuhan, anatomi kulit, fisiologi lateks, dan daya hasil lateks. Dari hasil penelitian menunjukkan bahwa karakter diameter pembuluh lateks, kecepatan aliran lateks, kadar karet kering, dan indeks hasil memiliki korelasi sangat nyata dan berpengaruh positif terhadap daya hasil lateks. Genotipe HP 92/309 dan HP 92/542 memiliki rerata hasil lateks paling tinggi yaitu masing-masing sebesar 46,82 g dan 46,42 g. Kedua genotipe tersebut potensial dikembangkan sebagai kandidat klon karet dengan karakter hasil lateks tergolong tinggi.
\end{abstract}

Kata kunci: Hevea brasiliensis, genotipe, korelasi, karakter komponen hasil, hasil lateks.

\begin{abstract}
The objective of the research was to know the correlation of yield component and latex yield characters of some promising rubber genotypes PP/07/04. As many as Five genotypes were planted at Plot Promotion trial, Sungei Putih Research Garden in 2004. The characters were observed in this research namely growth, skin anatomy, latex physiology, and latex yield potential. The research result showed that diameter of latex vessel, latex flow rate, dry rubber content, and yield index had more significant correlation and positive effect to latex yield. The latex yield of HP 92/309 and HP 92/542 genotypes were highest namely $46.82 \mathrm{~g}$ and $46.42 \mathrm{~g}$, respectively. Both genotypes have potential to be developed as promising rubber clones which have high latex yield character.
\end{abstract}

Keywords: Hevea brasiliensis, genotype, correlation, latex yield component, latex yield.

\section{PENDAHULUAN}

Karet merupakan tanaman perkebunan yang memiliki nilai penting dalam mengasilkan devisa negara. Pemerintah saat ini telah menargetkan agar Indonesia menjadi produsen utama karet dunia dengan cara meningkatkan produksi karet nasional sebesar 4 juta ton karet kering. Peningkatan produktivitas tersebut dapat dilakukan yang salah satunya dengan menggalakkan penanaman klonklon karet unggul yang memiliki produktivitas tanaman tinggi (Departemen Pertanian, 2014).

Kegiatan pemuliaan karet di Indonesia telah menghasilkan berbagai klon karet unggul dengan potensi produktivitas karet tergolong tinggi (Woelan, 2013). Klon karet anjuran skala komersial seperti PB 260, PB 330, PB 340, RRIC 100, BPM 24, IRR 112, dan IRR 118 telah 
banyak berkembang di berbagai perkebunan besar dan rakyat dengan produktivitas aktualnya dapat mencapai $2000-2500 \mathrm{~kg} / \mathrm{ha} / \mathrm{th}$. Untuk menghasilkan klon-klon karet unggul, maka kegiatan seleksi dan pemuliaan tanaman karet harus dilakukan secara berkesinambungan (Aidi-Daslin, 2011).

Program pemuliaan tanaman karet bertujuan untuk mendapatkan klon dengan potensi hasil lateks tinggi, pertumbuhan tanaman jagur, dan karakter sekunder yang baik. Kemajuan pemuliaan tanaman karet dapat diukur dari pencapaian peningkatan potensi produksi dari klon-klon unggul baru dibandingkan dengan klon sebelumnya. Selama empat generasi siklus pemuliaan tanaman karet dari tahun 1910 sampai dengan saat ini telah mencapai kemajuan yang cukup signifikan terhadap peningkatan hasil lateks yang telah mencapai lima kali lipat dibandingkan dengan tanaman seedling (Aidi-Daslin et al., 2009).

Menurut Woelan et al. (2013) karakter daya hasil lateks merupakan karakter kompleks yang sangat dipengaruhi oleh karakter komponen hasil. Karakter hasil dan komponen hasil merupakan karakter kuantitatif yang dikendalikan oleh banyak gen (poligenik). Analisis korelasi bertujuan untuk mempelajari pola hubungan karakter komponen hasil dengan daya hasil dan menyeleksi karakter komponen hasil yang memiliki korelasi nyata dengan karakter hasil (Falconer, 1981). Daya hasil merupakan karakter utama yang selalu menjadi tujuan perbaikan dalam setiap program pemuliaan tanaman. Keeratan hubungan antara karakter komponen hasil dengan daya hasil lateks dapat diduga dengan menghitung nilai koefisien korelasi antara dua karakter kuantitatif (Woelan et al., 2014).

Genotipe karet harapan PP/07/04 merupakan hasil seleksi Balai Penelitian Sungei Putih. Perakitan genotipe tersebut dilakukan pada tahun 1992 di kebun persilangan. Jumlah persilangan yang dilakukan untuk menghasilkan genotipe tersebut sebanyak \pm 31000 bunga dan menghasilkan sebanyak 828 tanaman F1. Tanaman F1 yang terseleksi dengan intensitas seleksi $1 \%$ berdasarkan sifat pertumbuhan dan hasil lateks digunakan sebagai materi seleksi yang diuji pada pengujian Plot Promosi. Pengujian tersebut dilakukan untuk mempercepat perolehan klon unggul harapan dengan karakter pertumbuhan tanaman jagur dan hasil lateks tinggi dengan waktu yang relatif singkat. Sebanyak lima genotipe yang merupakan bagian dari materi seleksi dari intensitas seleksi $1 \%$ berdasarkan pertumbuhan tanaman dan daya hasil lateks diuji pada penelitian ini. Tujuan penelitian ini adalah untuk mengetahui hubungan karakter komponen hasil dan daya hasil lateks dari beberapa genotipe karet harapan PP/07/04.

\section{BAHAN DAN METODE}

Pengujian genotipe karet harapan PP/07/04 dibangun di Kebun Percobaan Balai Penelitian Sungei Putih, Pusat Penelitian Karet pada tahun 2004, Kabupaten Deli Serdang - Provinsi Sumatera Utara yang terletak pada ketinggian $\pm 54 \mathrm{~m}$ di atas permukaan laut (dpl) dan berada pada posisi $3^{\circ}$ arah utara khatulistiwa. Klasifikasi jenis tanah digolongkan ke dalam tanah ultisol. Genotipe yang diuji pada penelitian ini yaitu HP92/211, HP92/309, HP92/366, HP92/542, dan HP92/726. Percobaan disusun dengan menggunakan rancangan acak kelompok (RAK) non faktorial. Masing-masing genotipe terdiri dari 60 tanaman yang dibagi menjadi tiga ulangan dan setiap ulangan terdiri dari 20 tanaman.

Pemeliharaan tanaman di lokasi pengujian seperti pembersihan areal dari gulma pengganggu tanaman dan pengendalian penyakit tanaman mengikuti standar pengelolaan kebun yang direkomendasikan oleh Pusat Penelitian Karet. Pemupukan dilakukan dua kali dalam setahun yaitu pada bulan Juni dan Desember dengan dosis masing-masing per aplikasi yaitu $175 \mathrm{~g} /$ pohon pupuk Urea, 100 g/pohon pupuk SP-36, 150 g/pohon pupuk MoP (Muriate of Potash) dan 38 g/pohon pupuk Kieserit. Parameter yang diamati pada penelitian ini seperti lilit batang tanaman, tebal kulit, jumlah 
pembuluh lateks, diameter pembuluh lateks, panjang alur sadap, kecepatan aliran lateks, indeks penyumbatan, kadar fospat anorganik, kadar sukrosa, kadar tiol, kadar karet kering, indeks hasil, dan hasil lateks.

Analisis data dilakukan dengan menggunakan analisis ragam (Anova). Jika masing-masing genotipe memiliki perbedaan nyata pada setiap parameter yang diamati maka dilakukan uji lanjut dengan menggunakan uji Tukey (Mattjik \& Sumertajaya, 2006). Analisis korelasi bertujuan untuk mengetahui keeratan hubungan antar karakter komponen hasil dan daya hasil lateks. Nilai korelasi pearson dihitung dengan menggunakan rumus Singh \& Chaudary (1979).

\section{HASIL DAN PEMBAHASAN}

\section{Korelasi antar Karakter Komponen Hasil dan Daya Hasil Lateks}

Keeratan hubungan antara komponen hasil dengan daya hasil lateks disajikan pada Tabel 1.Korelasi antar karakter fenotipe diperlukan dalam seleksi tanaman untuk mengetahui karakter yang dapat dijadikan petunjuk seleksi terhadap produktivitas tanaman yang tinggi (Suharsono et al., 2006; Wirnas et al., 2006). Tabel 1 menunjukkan bahwa karakter diameter pembuluh lateks, kecepatan aliran lateks, kadar karet kering, dan indeks hasil pada genotipe PP/07/04 memiliki hubungan yang berpengaruh sangat nyata dan bersifat positif terhadap daya hasil lateks dengan nilai koefisien korelasi (r) masing-masing karakter yaitu sebesar $0,65,0,75,0,66$, dan 0,89.

Tabel 1. Koefisien korelasi antar karakter komponen hasil dan daya hasil lateks

\begin{tabular}{|c|c|c|c|c|c|c|c|c|c|c|c|c|c|}
\hline Karakter & LB & PAS & TK & JPL & DPL & Suk & FA & Thi & KAL & IP & KKK & IH & HL \\
\hline LB & 1 & $0,94^{* * *}$ & $-0,18$ & 0,06 & 0,28 & 0,04 & 0,05 & 0,12 & $0,70^{* *}$ & $0,75^{* *}$ & 0,13 & 0,26 & $0,55^{*}$ \\
\hline PAS & & 1 & $-0,16$ & 0,10 & 0,29 & $-0,10$ & 0,20 & 0,13 & $0,66^{* *}$ & $0,67^{* *}$ & $-0,05$ & 0,25 & $0,57^{*}$ \\
\hline TK & & & 1 & 0,01 & 0,07 & 0,17 & 0,31 & 0,39 & 0,02 & $-0,23$ & $-0,06$ & 0,45 & 0,26 \\
\hline JPL & & & & 1 & 0,47 & $-0,05$ & 0,22 & $-0,32$ & 0,13 & 0,09 & 0,29 & $0,57^{*}$ & $0,54^{*}$ \\
\hline DPL & & & & & 1 & 0,32 & 0,19 & $-0,12$ & $0,58^{*}$ & 0,25 & 0,25 & $0,61^{* *}$ & $0,65^{* *}$ \\
\hline Suk & & & & & & 1 & $-0,47$ & $-0,19$ & 0,09 & $-0,11$ & 0,19 & 0,36 & 0,30 \\
\hline FA & & & & & & & 1 & $0,55^{*}$ & 0,43 & 0,27 & $-0,04$ & 0,35 & 0,24 \\
\hline Thi & & & & & & & & 1 & 0,35 & 0,26 & $-0,07$ & 0,26 & 0,16 \\
\hline KAL & & & & & & & & & 1 & $0,76^{* *}$ & 0,35 & $0,59^{*}$ & $0,75^{* *}$ \\
\hline IP & & & & & & & & & & 1 & $0,57^{*}$ & $-0,21$ & $-0,56^{*}$ \\
\hline KKK & & & & & & & & & & & 1 & 0,47 & $0,66^{* *}$ \\
\hline $\mathrm{IH}$ & & & & & & & & & & & & 1 & $0,89^{* *}$ \\
\hline HL & & & & & & & & & & & & & 1 \\
\hline
\end{tabular}

Keterangan: LB = Lilit batang; PAS = Panjang alur sadap; TK = Tebal kulit; JPL = Jumlah pembuluh lateks; $\mathrm{DPL}=$ Diameter pembuluh lateks; KAL $=$ Kecepatan aliran lateks; $\mathrm{IP}=$ Indeks penyumbatan; FA = Kadar fosfat anorganik; Suk = Kadar sukrosa; Thi $=$ Kadar thiol; KKK $=$ Kadar karet kering; IH: Indeks hasil; $\mathrm{HL}=$ Daya hasil lateks; $* *=$ berkorelasi sangat nyata pada uji t $.01 ; *=$ berkorelasi nyata pada uji t .05

Karakter lilit batang, panjang alur sadap, dan jumlah pembuluh lateks memiliki hubungan yang berpengaruh nyata dan bersifat positif terhadap daya hasil lateks dengan nilai koefisien korelasi masing-masing sebesar $0,55,0,57$, dan 0,54 , sedangkan indeks penyumbatan memiliki hubungan yang berpengaruh nyata namun bersifat negatif terhadap hasil lateks dengan nilai koefisien korelasi sebesar -0,56. Beberapa karakter yang diamati seperti tebal kulit, kadar fosfat anorganik, kadar sukrosa, dan kadar thiol memiliki hubungan yang tidak berpengaruh nyata terhadap daya hasil lateks dengan nilai koefisien korelasi masing-masing sebesar 0,26, 0,30, 0,24, dan 0,16. 
Menurut Gomez \& Gomez (1995), nilai korelasi antara dua karakter yang semakin mendekati +1 atau -1 , maka semakin erat hubungan antara kedua karakter tersebut. Nilai korelasi nyata dan bersifat positif mengindikasikan bahwa peningkatan suatu karakter yang satu akan menyebabkan peningkatan pada karakter yang lainnya, sedangkan nilai korelasi nyata dan bersifat negatif mengindikasikan bahwa peningkatan suatu karakter yang satu akan menyebabkan penurunan pada karakter lain (Aryana et al. 2011). Karakter yang memiliki keeratan hubungan yang nyata dengan hasil lateks dapat digunakan sebagai penduga dalam menyeleksi genotipe karet berdaya hasil tinggi (Woelan, 2013).

Hasil analisis korelasi pada penelitian ini menunjukkan bahwa kadar sukrosa, kadar fosfat anorganik, dan kadar thiol tidak dapat digunakan untuk menyeleksi klon karet berdaya hasil tinggi. Hal tersebut terlihat dari nilai korelasi pada karater tersebut tidak berpengaruh nyata terhadap hasil lateks. Kadar sukrosa tinggi tidak menjadi jaminan terhadap tingginya hasil lateks. Sumarmadji (1999) mengemukakan bahwa kadar sukrosa lateks tidak memiliki arti langsung sebagai gambaran potensi produksinya, namun dapat menggambarkan produksi aktual yang rendah diakibatkan sejumlah sukrosa tidak disintesis menjadi lateks. Kandungan fosfat anorganik dapat digunakan sebagai indikator terhadap energi dan metabolisme tanaman.

Kadar fosfat anorganik menggambarkan ketersediaan energi pada sel-sel pembuluh lateks untuk mengubah sukrosa menjadi partikel karet. Kisaran optimum kadar fosfat anorganik adalah 10 $20 \mathrm{mM}$, sehingga apabila tanaman memiliki kadar fosfat anorganik kurang dari $10 \mathrm{mM}$ mengindikasikan metabolisme sel kurang aktif, namun jika kadar fosfat anorganik lebih tinggi dari 20 $\mathrm{mM}$ mengindikasikan tanaman mengalami eksploitasi berlebih (over exploitation) atau terserang penyakit (Sumarmadji \& Tistama 2004).

Berdasarkan nilai koefisien korelasi tersebut menunjukkan bahwa lilit batang, jumlah pembuluh lateks, diameter pembuluh lateks, kecepatan aliran lateks, kadar karet kering, jumlah pembuluh lateks, panjang alur sadap, dan indeks hasil merupakan karakter komponen hasil yang memiliki hubungan cukup kuat dan bersifat positif terhadap daya hasil lateks, sedangkan indeks penyumbatan memiliki hubungan yang kuat namun bersifat negatif terhadap daya hasil lateks. Hal ini menunjukkan bahwa kedelapan karakter komponen hasil tersebut merupakan penciri yang sangat berpengaruh terhadap hasil lateks sehingga dapat digunakan sebagai kriteria seleksi pada program pemuliaan tanaman untuk memperoleh genotipe karet berdaya hasil tinggi.

\section{Karakter Komponen Hasil yang Mempengaruhi Pertumbuhan dan Daya Hasil Lateks}

Hasil analisis hubungan antara komponen hasil dengan daya hasil menunjukkan bahwa 5 genotipe karet berdaya hasil lateks tinggi dipengaruhi oleh karakter komponen hasil. Karakter komponen hasil pada masing-masing genotipe memiliki pengaruh yang berbeda terhadap hasil lateks. Karakter komponen hasil yang berkorelasi nyata terhadap daya hasil lateks dari beberapa genotipe karet harapan PP/07/04 disajikan pada Tabel 2. 
Tabel 2. Genotipe karet harapan PP/07/04 yang terseleksi berdasarkan karakter komponen hasil yang berkorelasi nyata terhadap daya hasil lateks

\begin{tabular}{|c|c|c|c|c|c|c|c|c|c|}
\hline \multirow[b]{2}{*}{ Genotipe } & \multicolumn{8}{|c|}{ Karakter komponen hasil } & \multirow[b]{2}{*}{$\begin{array}{c}\text { Hasil lateks } \\
\quad(\mathrm{g} / \mathrm{p} / \mathrm{s})\end{array}$} \\
\hline & $\begin{array}{l}\text { Lilit batang } \\
(\mathrm{cm})\end{array}$ & $\begin{array}{l}\text { Panjang alur } \\
\text { sadap }(\mathrm{cm})\end{array}$ & $\begin{array}{c}\text { Jumlah } \\
\text { pembuluh } \\
\text { lateks }\end{array}$ & $\begin{array}{c}\text { Diameter } \\
\text { pembuluh } \\
\text { lateks }(\mu \mathrm{m})\end{array}$ & $\begin{array}{l}\text { Kecepatan } \\
\text { aliran lateks } \\
\text { (ml/menit) }\end{array}$ & $\begin{array}{c}\text { Indeks } \\
\text { penyumbatan } \\
(\%)\end{array}$ & $\begin{array}{l}\text { Kadar karet } \\
\text { kering } \\
(\%)\end{array}$ & $\begin{array}{c}\text { Indeks hasil } \\
(\%)\end{array}$ & \\
\hline HP 92/211 & $70,50 \mathrm{~b}$ & $38,96 \mathrm{~b}$ & $10,67 \mathrm{~b}$ & $21,46 \mathrm{~b}$ & $16,41 \mathrm{c}$ & $27,76 \mathrm{~b}$ & $32,33 \mathrm{ab}$ & $14,26 \mathrm{~b}$ & $38,99 \mathrm{~b}$ \\
\hline HP 92/309 & $63,83 \mathrm{c}$ & $34,17 \mathrm{c}$ & $15,50 \mathrm{a}$ & $26,42 \mathrm{a}$ & $20,64 b$ & $23,22 \mathrm{c}$ & $34,97 \mathrm{a}$ & $17,61 \mathrm{a}$ & $46,82 \mathrm{a}$ \\
\hline HP 92/366 & $79,46 \mathrm{a}$ & $44,88 \mathrm{a}$ & $15,83 \mathrm{a}$ & $23,21 b$ & $24,40 \mathrm{a}$ & $36,58 \mathrm{a}$ & $34,93 \mathrm{a}$ & $11,93 \mathrm{c}$ & $38,97 \mathrm{~b}$ \\
\hline HP 92/542 & $76,88 \mathrm{a}$ & $43,71 \mathrm{a}$ & $16,50 \mathrm{a}$ & $27,29 a$ & $33,02 \mathrm{a}$ & $27,94 b$ & $35,32 \mathrm{a}$ & $18,52 \mathrm{a}$ & $46,42 \mathrm{a}$ \\
\hline HP 92/726 & $56,38 \mathrm{~d}$ & $29,96 \mathrm{~d}$ & $17,00 \mathrm{a}$ & $22,29 a$ & $6,43 \mathrm{~d}$ & $17,75 \mathrm{~d}$ & $28,91 \mathrm{~b}$ & $7,27 \mathrm{~d}$ & $39,36 \mathrm{~b}$ \\
\hline
\end{tabular}

Keterangan: angka-angka yang diikuti oleh huruf yang sama menunjukkan tidak berbeda nyata menurut uji Tukey pada $\alpha .05$ 
Genotipe HP 92/211 memiliki hasil lateks tinggi yang dipengaruhi oleh karakter lilit batang dan kadar karet kering. Genotipe HP 92/309 memiliki hasil lateks tinggi yang dipengaruhi oleh karakter diameter pembuluh lateks, indeks penyumbatan, kadar karet kering, dan indeks hasil. Genotipe HP 92/366 memiliki hasil lateks tinggi dipengaruhi oleh karakter lilit batang, panjang alur sadap, kecepatan aliran lateks, dan kadar karet kering. Genotipe HP 92/542 memiliki hasil lateks tinggi yang dipengaruhi oleh karakter lilit batang, panjang alur sadap, jumlah pembuluh lateks, diameter pembuluh lateks, kecepatan aliran lateks, kadar karet kering, dan indeks hasil. Genotipe HP 92/726 memiliki hasil lateks tinggi yang dipengaruhi oleh karakter jumlah pembuluh dan indeks penyumbatan. Gambar 1 memperlihatkan hasil lateks selama 6 tahun sadap. Hasil lateks dari kelima genotipe selama 6 tahun sadap sangat berfluktuatif. Hasil lateks pada tahun pertama masih tergolong rendah kecuali pada genotipe HP 92/542, namun sejalan bertambahnya umur tanaman terlihat hasil lateks pada kelima genotipe cenderung naik. Genotipe HP 92/309 dan HP 92/542 memiliki rerata hasil lateks yang paling tinggi, sedangkan yang paling rendah terdapat pada genotipe HP 92/366 dan HP 92/726.

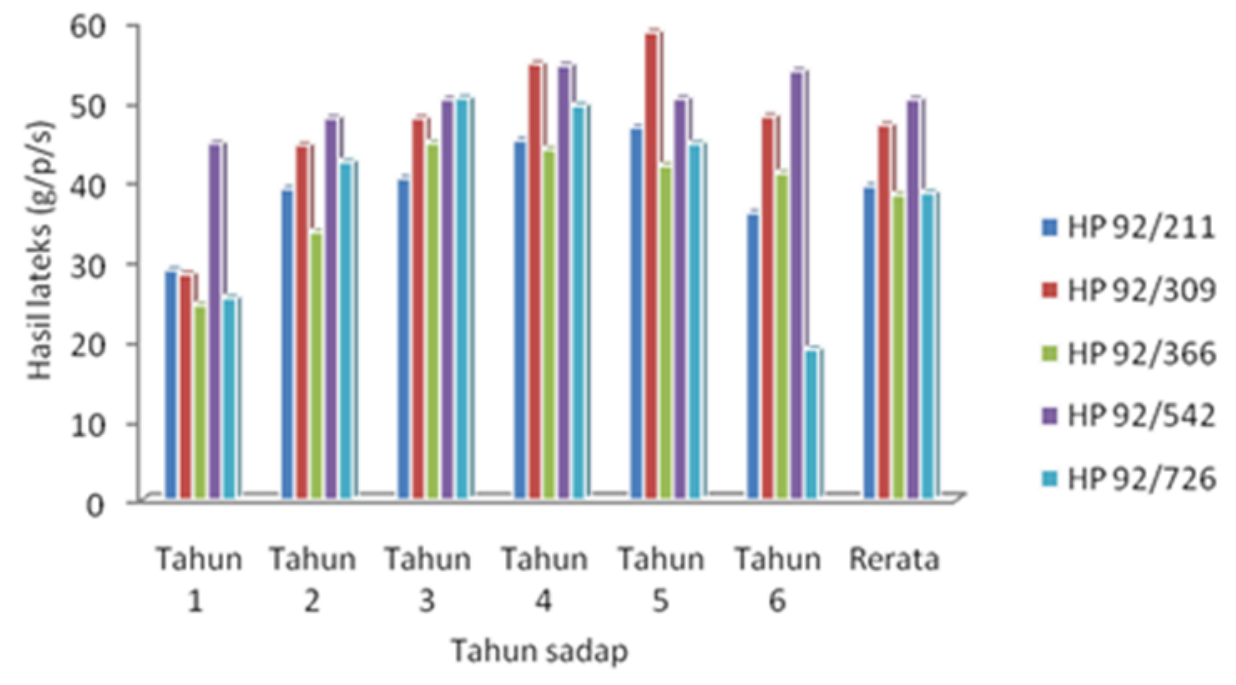

Gambar 1. Hasil lateks beberapa genotipe PP/07/04 selama enam tahun sadap

\section{Karakter Fisiologi Lateks dari Beberapa Genotipe PP/07/04}

Selain karakter komponen hasil yang berkaitan erat terhadap daya hasil, diagnosis lateks juga berperan penting untuk menduga potensi hasil lateks. Terdapat tujuh karakter fisiologi yang dapat digunakan dalam analisis diagnosis lateks yaitu kadar sukrosa, fosfat anorganik, thiol, magnesium, $\mathrm{pH}$, total solid content dan bursting index (Sumarmadji 1999). Sebanyak tiga karakter fisiologi dari tujuh karakter fisiologi yang diamati pada penelitian ini yaitu kadar sukrosa, kadar fosfat anorganik, dan kadar thiol (Tabel 3). Kadar sukrosa merupakan bahan baku dalam sintesis partikel karet (poli isoprena). Selain itu, sukrosa juga berperan penting pada proses pertumbuhan tanaman. Menurut Gohet et al. (1996), produksi lateks dan pertumbuhan berkompetisi dengan kuat dalam penggunaan sukrosa. Kadar fosfat anorganik berhubungan dengan aktivitas metabolisme dalam sel pembuluh lateks. Kadar fosfat anorganik tinggi mencerminkan metabolisme yang aktif dalam biosintesis lateks. 
Kadar thiol berfungsi sebagai aktivator berbagai enzim dan berhubungan dengan stabilitas membran lutoid untuk memperpanjang lama aliran lateks.

Tabel 3. Karakter kadar sukrosa, kadar fosfat anorganik, dan kadar thiol dari 5 genotipe terseleksi

\begin{tabular}{ccccc}
\hline Genotipe & \multicolumn{3}{c}{ Karakter fisiologi } & $\begin{array}{c}\text { Kategori } \\
\text { metabolisme }\end{array}$ \\
\cline { 2 - 4 } & $\begin{array}{c}\text { Kadar sukrosa } \\
(\mathrm{mM})\end{array}$ & $\begin{array}{c}\text { Kadar fosfat } \\
\text { anorganik }(\mathrm{mM})\end{array}$ & $\begin{array}{c}\text { Kadar thiol } \\
(\mathrm{mM})\end{array}$ & tinggi \\
HP 92/211 & $5,29 \mathrm{~b}$ & $12,02 \mathrm{~b}$ & $0,75 \mathrm{c}$ & rendah \\
HP 92/309 & $12,09 \mathrm{a}$ & $10,58 \mathrm{bc}$ & $0,42 \mathrm{c}$ & tinggi \\
HP 92/366 & $5,57 \mathrm{~b}$ & $9,99 \mathrm{bc}$ & $0,34 \mathrm{c}$ & tinggi \\
HP 92/542 & $4,61 \mathrm{~b}$ & $15,47 \mathrm{a}$ & $0,57 \mathrm{~b}$ & tinggi \\
\hline HP 92/726 & $4,78 \mathrm{~b}$ & $9,42 \mathrm{bc}$ & $0,39 \mathrm{c}$ & \\
\hline
\end{tabular}

Keterangan: angka-angka yang diikuti oleh huruf yang sama menunjukkan tidak berbeda nyata menurut uji Tukey pada $\alpha .05$

Hasil lateks tinggi saat penyadapan dapat dicapai apabila regenerasi sel berjalan dengan baik. Ketiga karakter fisiologi tersebut dapat digunakan sebagai gambaran awal untuk menentukan tingkat metabolisme masing-masing genotipe. Lima genotipe yang terseleksi berdasarkan karakter daya hasil dan komponen hasil tersebut perlu ditambahkan informasi awal tingkat metabolisme tanaman yang tergolong ke dalam metabolisme tinggi (quick starter) atau metabolisme rendah (slow starter).

Informasi ini diperlukan untuk menentukan teknik penyadapan yang tepat agar potensi hasil lateks pada masing-masing genotipe dapat diperoleh secara optimal. Karakter kadar sukrosa, kadar fosfat anorganik, dan kadar thiol 5 genotipe terseleksi yaitu HP 92/211, HP 92/309, HP 92/366, HP 92/542, dan HP 92/726 disajikan pada Tabel 21. Tabel 21 menunjukkan tingkat metabolisme masingmasing genotipe berdasarkan tiga karakter fisiologi (kadar sukrosa, kadar fosfat anorganik, dan kadar thiol). Berdasarkan ketiga karakter tersebut dapat diketahui informasi awal genotipe yang tergolong metabolisme tinggi terdapat pada genotipe HP 92/211, HP 92/366, HP 92/542, dan HP 92/726 sedangkan metabolisme rendah terdapat pada genotipe HP92/309.

Genotipe HP 92/211, HP 92/366, HP 92/542, dan HP 92/726 memiliki kadar sukrosa yang lebih rendah dibandingkan dengan genotipe HP 92/309, namun kadar fosfat anorganiknya tergolong tinggi. Kadar sukrosa yang rendah dengan kadar fosfat anorganik tinggi pada genotipe HP 92/211, HP 92/366, HP 92/542, dan HP 92/726 mencerminkan bahwa metabolisme berjalan aktif dalam mensintesis sukrosa menjadi partikel karet yang diikuti oleh kadar thiol masih dalam batas normal, kecuali pada genotipe HP 92/366 dan HP 92/726 yang terindikasi stres akibat ekploitasi penyadapan.

Kadar sukrosa paling tinggi dengan kadar fosfat anorganik tergolong tinggi yang terdapat pada genotipe HP 92/309 mencerminkan bahwa metabolisme berjalan lambat dalam mensintesis sukrosa menjadi partikel karet. Untuk menghasilkan lateks tinggi pada genotipe yang memiliki metabolisme rendah dapat dilakukan penyadapan dengan menggunakan aplikasi stimulan.

Menurut Sumarmadji (1999), pengetahuan tentang metabolisme tanaman sangat penting untuk diketahui dalam mengoptimalkan sistem eksploitasi tanaman. Peningkatan produksi lateks oleh stimulasi dicirikan oleh besarnya penurunan indeks penyumbatan, kadar karet kering, dan peningkatan kadar fosfat anorganik. Namun, untuk menghindari pengaruh jangka panjang, maka teknik eksploitasi perlu dipertimbangkan ketersediaan kadar sukrosa dan kadar thiol dalam lateks serta aktivitas enzim superoksida dismutase. Hal ini penting diketahui agar tanaman dapat berproduksi secara optimal sesuai dengan kapasitas tanaman dalam menghasilkan lateks dan menjaga tidak terjadinya kekeringan alur sadap. 


\section{KESIMPULAN}

Berdasarkan hasil penelitian tersebut dapat disimpulkan bahwa karakter diameter pembuluh lateks, kecepatan aliran lateks, kadar karet kering, dan indeks hasil memiliki korelasi sangat nyata dan bersifat positif terhadap daya hasil lateks. Genotipe HP 92/309 dan HP 92/542 memiliki rerata hasil lateks yang paling tinggi yaitu masing-masing sebesar 46,82 g dan 46,42 g. Kedua genotipe tersebut potensial dikembangkan sebagai klon karet harapan dengan karakter hasil lateks tergolong tinggi.

\section{DAFTAR PUSTAKA}

Aidi-Daslin, Woelan, S., Lasminingsih, M., Hadi H. 2009. Kemajuan pemuliaan dan seleksi tanaman karet di Indonesia. Pros Pemuliaan Tanaman Karet. 2005.p50-59.

Aidi-Daslin. 2011. Evaluasi pengujian lanjutan klon karet IRR seri 200 pada masa tanaman belum menghasilkan. J Penelitian Karet. 29 (2): 93-101.

Aryana, I.G.P.M., Basuki. N., Kuswanto. 2011. Sidik lintas padi beras pada tiga lingkungan tumbuh berbeda. JAgroteksos 21(1): 45-59.

Departemen Pertanian. 2014. Luas Areal, Produksi dan Produktivitas Perkebunan di Indonesia tahun 2013 [internet].[diunduh 05 Mei 2015]. Tersedia pada: http://www.pertanian.go.id/Indikator/tabel-3-prod-lsareal-prodvitas-bun.pdf.

Falconer, D.S. 1981. Introduction to Quantitative Genetic. New York (US). The Ronald Company Pr.

Gohet, E., Prevot, J.E., Eschbach, J.M., Clement, A., dan Jacob, J.L. 1996. Clone, croisance at stimulation to incease latex production. J. Plantations. p30-38.

Gomez, K.A., dan Gomez, A.A. 1995. Prosedur Statistika untuk Penelitian Pertanian. E. Sjamsudin, JS Baharsjah, penerjemah . Jakarta [ID]: UI Pr.

Mattjik, A.A., dan Sumertajaya, I.M. 2006. Perancangan Percobaan dengan Aplikasi SAS dan Minitab. Bogor (ID): IPB Pr.

Singh, R.K., dan Chaudary, B.D. 1977. Biometrical Methods In Quantitative Genetics Analysis. Kalyani Publishers. Indiana New Delhi. 304p.

Suharsono., Jusuf, M., dan Paserang, A.P. 2006. Analisis ragam, heritabilitas, dan pendugaan kemajuan seleksi populasi F2 dari persilangan kedelai kultivar Slamet x Nokonsawon. J Tan Trop. 9 (2): 86-93.

Sumarmadji. 1999. Respon karakter fisiologi dan produksi lateks beberapa klon tanaman karet terhadap stimulasi etilen. [disertasi]. Bogor (ID): Institut Pertanian Bogor.

Sumarmadji dan Tistama, R. 2004. Deskripsi klon karet berdasarkan karakter fisiologi lateks untuk menetapkan sistem eksploitasi yang sesuai. J Penelitian Karet 22(1): 27-40.

Wirnas, D., Widodo, I., Sobir., Trikoesoemaningtyas., Sopandi, D. 2006. Pemilihan karakter agronomi untuk menyusun indeks seleksi pada 11 populasi kedelai generasi F6. Bul Agron. 34:19-24.

Woelan, S. 2013. Peta pautan genetik dan analisis QTL tanaman karet (Hevea brasiliensis Muell Arg.) pada populasi hasil persilangan RRIM 600 dan PN 1546 sebagai dasar strategi peningkatan produksi lateks. [disertasi]. Medan (ID): Universitas Sumatera Utara.

Woelan, S., Sayurandi, dan Pasaribu, S.A. 2013. Karakter fisiologi, anatomi, pertumbuhan dan hasil lateks klon IRR seri 300. J Penelitian Karet 31(1): 1-12.

Woelan, S., Sayurandi., dan Irwansyah, E. 2014. Variability of genetic rubber plant (Hevea brasiliensis Muell Agr.) from Interspesific Crossing. J Indonesian Rubber Research 32(2): 109-121. 